\title{
Modeling of exothermic synthesis of composite with oxide inclusions
}

\author{
Anna Knyazeva ${ }^{1,2, *}$, and Nahum Travizkii ${ }^{3}$ \\ ${ }^{1}$ Tomsk Polytechnic University, 634050 Lenin Av., Tomsk, Russia \\ 2 Institute of Strength Physics and Material Science, 634055 Akademicheskii pr., 2/4, Tomsk, \\ Russia \\ ${ }^{3}$ University of Erlangen-Nuremberg, D-91058 Martensstr,5, Erlangen, Germany
}

\begin{abstract}
The model is suggested for composite synthesis on the base of metallic matrix with inclusions of aluminum oxide at the conditions close to thermal explosion. Chemical reactions are described with the help of two summary stages. The melting, the dependence of reaction rates on pressure and reaction retardation by the product layer are taken into account. It was shown that during reactions proceeding in any regime the formation of final composition of the matrix does not occur. It agrees with known experimental data.
\end{abstract}

\section{Introduction}

Combustion synthesis (the methods of metallothermy and self-propagating hightemperature synthesis) are widely used in various branches of science and technology [1]. The past few years the numerous research techniques of metal matrix composites appear [2], where metallothermy has been used. Among various metal matrix composites very popular have become the composite materials based on light metal alloys. Carbides, oxides, nirides, borides, silicides and fine intermetallides are used as reinforcing inclusions [3]. The principal cause of thermite processes employment is connected with their small energy consumption. However, the difficulties exist in the governing of metallothermic processes with high heat release. The changing in the ratio of the material, adding oxidizers or inert inclusions, external fields of various physical nature etc. are used to optimize the synthesis process. Mathematical modeling serves also to this goal. So, to obtain the composites with minimal porosity, synthesis during isostatic pressing are used. Modeling of this process $[4,5]$ allows studying the conversion regimes. Synthesis together with the extrusion was studied theoretically by authors of [6,7]. However only in $[8,9]$, coupling models were constructed. The influence of inert particles on the combustion and thermal explosion regimes was investigated in $[10,11]$ based on conjugate models. Papers $[12,13]$ includes in the models the detailed reaction mechanisms for investigation of intermetallic composite synthesis on the substrate surface.

\footnotetext{
*Corresponding author: anna-knyazeva@mail.ru
} 
This paper suggests the thermal explosion model in cylindrical reactor and takes into consideration two summary reactions: aluminum oxide synthesis with the reduction reaction and composite solution formation, correspondingly to experimental data [14].

\section{Model formulation}

Corresponding to experimental data [14], the green powder mixture placed in cylindrical reactor contains $\mathrm{Al}, \mathrm{Fe}_{2} \mathrm{O}_{3} ; \mathrm{Fe} ; \mathrm{Cr}$; $\mathrm{Ni}$ in given proportion. The heating of powder mixture can be carried out from the side of lateral surfaces of cylindrical reactor (a) or from the side of plunger, which assists the mixture compaction (b). In a first case, the heating can be assumed as uniform along the reactor height, and hence, the temperature distribution and composition will depend only on radial coordinate. In the approximation of thin layers of the reactor, one-dimensional thermal conductivity equation in cylindrical coordinate system takes a place

$$
c \rho \frac{\partial T}{\partial t}=\frac{1}{r} \frac{\partial}{\partial r}\left(\lambda r \frac{\partial T}{\partial r}\right)+W
$$

Where the heat capacity $c$, density $\rho$ and thermal conductivity coefficient depend on the composition and porosity $\theta$, and the function $W$ is the total heat of chemical reactions running in the mixture under the heating. Two summary reactions can be assigned here

$$
\begin{gathered}
2 \mathrm{Al}(\mathrm{L})+\mathrm{Fe}_{2} \mathrm{O}_{3} \rightarrow \mathrm{Al}_{2} \mathrm{O}_{3}+2 \mathrm{Fe} \\
4.9 \mathrm{Fe}+3.2 \mathrm{Cr}+1.9 \mathrm{Ni} \rightarrow 10 \mathrm{Fe}_{0.49} \mathrm{Cr}_{0.32} \mathrm{Ni}_{0.19}
\end{gathered}
$$

Formal approach permits to write for reaction rates the following expressions

$$
\varphi_{1}=z_{1} C_{1}^{2} C_{2} \Phi\left(C_{6}+C_{7}\right) \exp \left(-\frac{E_{1}}{R T}\right) \text { and } \varphi_{2}=z_{2} C_{3}^{4.9} C_{4}^{3.2} C_{5}^{1.9} \Phi\left(C_{6}+C_{7}\right) \exp \left(-\frac{E_{2}}{R T}\right)
$$

where $C_{k}$ are mass concentrations or species; $E_{1}$ and $E_{2}$ are the activation energies for reactions. $z_{1}, z_{2}$ are pre-exponential factors; $R$ is universal gas constant; the function $\Phi$ reflects the reaction retardation due to the reaction product accumulation.

The mass conservation laws are correct for both reactions:

$$
\sum_{k=1}^{7} v_{k i} m_{k}=0, i=1,2,
$$

where $v_{k i}$ are stoichiometric coefficients for $\mathrm{k}$-species in the reaction I; $m_{k}$ are molar masses. Kinetical equations are written for species

$$
\rho \frac{d C_{k}}{d t}=w_{k}
$$

where $w_{k}=v_{k 1} m_{k} \varphi_{1}+v_{k 2} m_{k} \varphi_{2}, k=1,2, \ldots, 7$

The porosity changes in accordance with kinetical equation

where $P$ is applied load.

$$
\frac{d \theta}{d t}=\varphi(\theta, T, P)
$$


The melting is taken into account through the heat capacity change. Additionally, to diminish the reaction temperature the inert particles could be added to the reaction mixture. It is taken into account trough the heat capacity evaluation also.

When the reaction rates depend on the pressure, usual exponent in Arrhenius equation is changed by the function

$$
\exp \left(-\frac{E_{k}-\alpha_{k} \gamma_{k} P}{R T}\right),
$$

where $\gamma_{k}$ is activation volume, $\alpha_{k}$ is some experimental constant. This law speak that reaction can be activated not only when temperature growths but due to pressure work over activation volume change [15].

The boundary conditions take into account the radiation heating from the source with given temperature and heat losses (or heat accumulation) in the reactor walls.

The problem was solved numerically. Parameters were found in literature and/or were calculated based thermodynamics.

\section{Some results}

The dynamics of the process depends essentially on reactor size, heating rate, heat exchange conditions and equivalent properties evolution. It was shown numerically that controlling the reactions could be carried out with the help of heating rate and inert particles addition. The first occurs when external source temperature changes. Example of the various reaction regimes are presented in Fig.1,a,b The temperature of external source equals to $1800 \mathrm{~K}$ (Figures a) and $2120 \mathrm{~K}$ (Figures b).
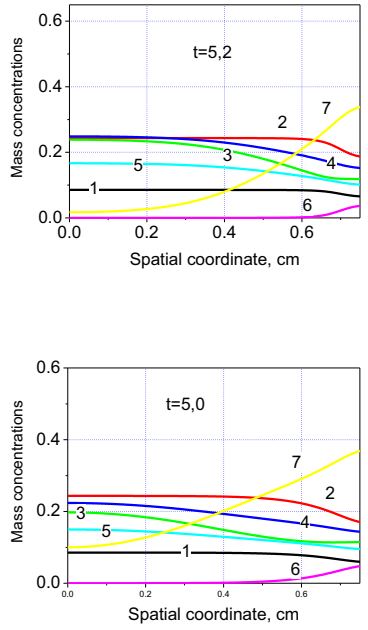

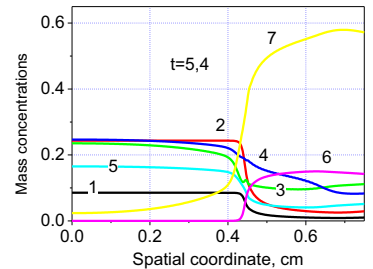

a

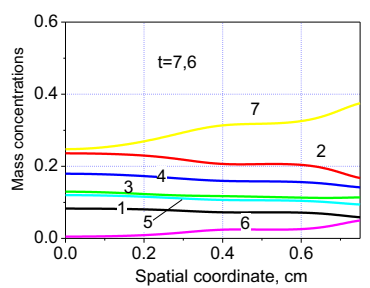

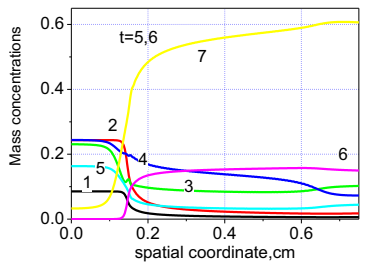

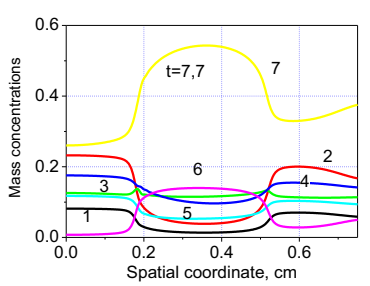

b

Fig.2. Spatial distribution of reagents and reaction products for different time moments; a) $T_{W}=1800 \mathrm{~K}$, b) $T_{W}=2120 \mathrm{~K}$. 1 . - $\mathrm{Al}$, 2. - $\mathrm{Fe}_{2} \mathrm{O}_{3}$; 3. - $\mathrm{Fe}$; 4. - $\mathrm{Cr}$, 5. - $\mathrm{Ni}$, 6. - $\mathrm{Al}_{2} \mathrm{O}_{3}$, 7. $\mathrm{Fe}_{0.49} \mathrm{Cr}_{0.32} \mathrm{Ni} i_{0.19}$

External heating is broken when temperature of reactor wall reaches $900 \mathrm{~K}$. During a more slow heating, the reaction zone forms which propagates then to reactor center 
(Fig.1,a). For high rate heating, the reaction starts near the walls also, however it accelerates then in a volume (Fig.1,b). It was found that for more fast heating, reactions stop near the walls just beginning.

Generally, interrelation between different mechanisms of temperature change in each point (thermal conductivity, chemical heat) accompanying the properties change leads to not uniform composition change. It was observed experimentally [14]. Note, for thick reactor walls, thermal conductivity problem will conjugate. The walls play double function. On the one hand, they need a more heat for the heating, on the other hand, they are additional heat sources when external heating is broken, and the reactions do not completed.

The role of endothermic stage in the thermal explosion was discussed in $[16,17]$ for simple conditions. Suggested here model allows investigate composition change varying the heating conditions. It was detected the first reaction (Fe-reducing) completes often quickly. However matrix formation can continue when reactor is cooling. That agrees with experiment also.

This work was made under support of Russian academic excellence program.

\section{References}

1. F.Kh. Urakaev, K.A. Akmalaev, E.S. Orynbekov, B.D. Balgysheva, D.N. Zharlykasimova, Metallurgical and Materials Trans. B 47B, 2 (2016)

2. E. Fra, A. Janas, A. Kolbus, E. Olejnik, Archives of foundry engineering, 9, 2 (2009)

3. A. Ibrahim, F. Mohamed, E. Lavernia, J. Materials Sc. 26, (1997)

4. L.M. Buchatskii, S.I. Khudyaev, G.V. Shkadinskaya, Combust., Explosion and Shock Waves 28, 1 (1992)

5. V.K. Smolyakov, Combust., Explosion and Shock Waves 34, 4 (1998)

6. L.S. Stel'makh, N.N. Zhilyaeva, A.S. Stolin, J. Eng. Phys. Thermophys. 63, 5 (1992)

7. V. E. Ovcharenko, O.V. Lapshin, I.S. Ramazanov, Combust., Explosion and Shock Waves 42, 3 (2006)

8. A.G. Knyazeva, N.K. Evstigneev, Procedia Computer Sci. 1, 1. (2010)

9. N.K. Evstigneev, A.G. Knyazeva, J. Appl. Mech. Techn. Phys. 52, 3 (2011)

10. A.G. Knyazeva, A.A. Chachshina, Combust., Explosion, and Shock Waves 40, 4 (2004)

11. A.A. Chachshina, A.G. Knyazeva, Chemistry for sustainable development 13, 2 (2005)

12. S.N. Sorokova, A.G. Knyazeva, Theor. Found. Chem. Eng. 42, 4 (2008)

13. S.N. Sorokova, A.G. Knyazeva, Theor. Found. Chem. Eng. 44, 2 (2010)

14. N. Travitzky, P. Kumar, K.H. Sandhage, R. Janssen, N. Claussen, Material Sci. Eng. A 244 (2003)

15. A.G. Knyazeva, Combust., Explosion and Shock Waves 28, 1 (1992)

16. M.B. Borovikov, U.I. Gol'dshleger, I.A. Burovoi, Combus., Explosion, and Shock Waves 20, 1 (1984)

17. M.B. Borovikov, U.I. Gol'dshleger, Combust., Explosion, and Shock Waves 17, 5 (1981) 